\title{
Sentidos da pesquisa na prática profissional de enfermeiras assistenciais
}

\author{
Meanings of research in the professional practice of clinical nurses \\ Sentidos de la investigación en la práctica professional de enfermeras asistenciales
}

\begin{abstract}
Maria Helena Menezes Guariente', Márcia Fontão Zago', Zeneide Soubhia', Maria do Carmo Lourenço Haddad'
\end{abstract}

'Universidade Estadual de Londrina. Escola de Enfermagem. Londrina, PR

Submissão: 02/09/2009

Aprovação: 23/05/2010

\section{RESUMO}

O objetivo do estudo foi analisar os sentidos dados a atividade investigativa atribuídos pelas enfermeiras assistenciais participantes de um núcleo de apoio a pesquisa. Foi utilizado o referencial teórico da antropologia interpretativa e o estudo de caso etnográfico. Para a coleta de dados empregamos a entrevista semi-estruturada individual e grupal, análise de documentos e de depoimentos e o diário de campo. Pela análise interpretativa do discurso de 36 participantes identificamos Quatro núcleos de sentidos: valoração da atividade, pesQuisar é aprender, movimentos da atividade, a atividade é trabalho árduo Que demanda esforço pessoal. Compreendemos Que capacitação em pesQuisa, apoiada pela organização e desejada pela enfermeira, consubstancia-se como estratégia científico-pedagógica na formação de enfermeiras, com repercussões positivas para a assistência prestada.

Descritores: Pesquisa em enfermagem; Enfermeiras clínicas; Cultura.

\section{ABSTRACT}

The aim of this study was to analyze the meanings given to investigative research by nurse clinicians enrolled in a research support group. The interpretive anthropology theoretical frame was used along with an ethnographic case study. Data was collected through semi-structured individual and group interviews, document and statement analysis as well as field diary notes. The statements of 36 participants were analyzed interpretively identifying four categories: activity's value, researching is learning, the movements about the activity, the activity is hard work that demands personal effort. We understand that once research training initiative is supported by the organization and desired by the nurse, it becomes a scientific-pedagogical strategy for academic nursing formation with positive repercussions to care assistance.

Key words: Nursing research; Nurse clinicians; Culture.

\section{RESUMEN}

El objetivo del estudio ha sido analizar el sentido dado a la actividad investigativa atribuido por las enfermeras asistenciales participantes de un núcleo de apoyo a la investigación. Fue utilizada la referencia teórica de la antropología interpretativa y el estudio del caso etnográfico. Para la colecta de datos se ha empleado la entrevista semi-estructurada individual y grupal, el análisis de documentos y de declaraciones, y el diario de campo. Por el análisis interpretativo del discurso de 36 participantes se han podido identificar cuatro núcleos de sentidos: valoración de la actividad, investigación como aprendizaje, movimientos de la actividad, la actividad como trabajo arduo que demanda esfuerzo personal. Se entiende que la capacitación en investigación, apoyada por la organización, y deseada por la enfermera, se afianza como estrategia científico-pedagógica en la formación de enfermeras, con repercusiones positivas para la asistencia prestada.

Descriptores: Investigación en enfermería; Enfermeras clínicas; Cultura. 


\section{INTRODUÇÃO}

A pesquisa é uma atividade que possibilita a reflexão e a transformação da prática profissional. As enfermeiras, para acompanharem a acirrada evolução técnico-científica vigente na era da informação e exercer com Qualidade o seu papel social, necessitam estar em constante desenvolvimento passando a incluir a peseuisa nas atividades da prática-assistencial, unindo o saber fazer e pensar - mediante o processo investigativo, culminando no refazer $^{(1)}$.

No Brasil, a pesquisa em enfermagem teve grande avanço com a implantação dos programas de pós-graduação a partir de 1972 , tendo como perfil os enfermeiros da área acadêmica ${ }^{(2)}$.

O processo de pesquisar pela enfermeira tem sido foco de vários autores brasileiros. Reconhece-se Que as enfermeiras assistenciais a valorizam e têm procurado realizá-la ${ }^{(3-7)}$. Entre as dificuldades relatadas por elas para desenvolverem trabalhos científicos estão: a inexistência no acompanhamento científico para tal tarefa; não serem consumidoras de pesQuisa; a falta do hábito de reflexão crítica da prática profissional; a pouca desenvoltura em escrever e divulgar as experiências e atividades profissionais. A estas dificuldades acrescentam-se a falta de incentivo pela instituição empregadora, como ainda a inexistência de um serviço de apoio ${ }^{(3-4)}$.

Os estudos citados apontam Que Quando a enfermeira estabelece para si a meta de realizar um trabalho científico, o realiza pela necessidade e motivação pessoal/profissional, em algumas situações com o apoio da instituição empregadora. Quando encontra dificuldades de ordem instrumental em relação ao método científico e a redação, tenta superar com a ajuda de docentes e profissionais da área da saúde ${ }^{(4)}$. A experiência de enfermeiras assistenciais de desenvolverem pesquisa nas organizações hospitalares revela Que esse é um processo Que ainda está sendo apreendido por estas profissionais e administradores e, por isso, nesses ambientes não há uma política definida Que proporcione a realização dessa atividade. Portanto, o processo de pesquisar é determinado pela própria enfermeira, Que sofre influência do contexto institucional ${ }^{(4-}$ 5). Estabelecer ambiente favorável, estimular as enfermeiras a Questionar e avaliar a prática faz parte de um agrupamento de ações para o enfrentamento das barreiras Que impedem ou dificultam a utilização da pesQuisa no cotidiano profissional ${ }^{(4)}$.

Acontecimentos recentes são as parcerias entre instituições de ensino e empregadoras da saúde, visando o aprimoramento do seu pessoal, apoio às enfermeiras na efetivação de pesQuisas com a formação de grupos de estudo e núcleos de pesQuisa entre outras atividades. Vários grupos, comissões e núcleos de pesQuisa, centro de estudos e de práticas educativas em Enfermagem vêm sendo criados com a finalidade de estimular e auxiliar as enfermeiras no desenvolvimento e divulgação de pesQuisa, como importante recurso no seu processo de trabalho ${ }^{(4-6)}$. Estes são movimentos Que apontam inovações e mudança na cultura das organizações.

Seguindo essa tendência, a Diretoria de Enfermagem do Hospital Universitário Regional do Norte do Paraná (HURNP) criou em 1999 o Núcleo de Pesquisa em Enfermagem (NUPE), com o propósito de apoiar as enfermeiras na realização de pesquisas. Nos Quatro anos de funcionamento (1999 a 2002), o núcleo desenvolveu diversas atividades como encontros científicos, workshops, cursos e realização de pesquisas de interesse das participantes, cujos resultados tiveram implicações na Qualidade do cuidado de enfermagem prestado, fornecendo o apoio necessário e financiamento para a divulgação destes em eventos científicos e publicações $^{(5,7)}$.

A necessidade de identificar como a pesquisa foi percebida no cotidiano das enfermeiras apoiadas pelo NUPE, nos mobilizou na investigação da problemática: Qual o sentido da atividade investigativa no desenvolvimento profissional e na prática assistencial de enfermeiras participantes de um serviço de incentivo à pesQuisa?

Assim, esse estudo teve como objetivo analisar os sentidos dados a atividade investigativa atribuídos pelas enfermeiras assistenciais participantes do NUPE.

\section{REFERENCIAL TEÓRICO-METODOLÓGICO}

Buscamos na Antropologia Interpretativa a base teórica e metodológica para a realização do estudo. O conceito-chave dessa abordagem teórica é cultura como o conjunto de regras e padrões Que orienta e dá sentido às idéias e às práticas de um determinado grupo social. Entretanto, a análise da cultura é semiótica, o Que leva o pesquisador a considerar esses sentidos, relacionando-os às características dos elementos do grupo e ao contexto social, interpretando-os compreensivamente em saberes diferentes ${ }^{(8)}$.

O estudo de caso etnográfico foi a estratégia metodológica selecionada, possibilitando centrar o nosso interesse na capacitação de peseuisar das enfermeiras participantes do núcleo, tendo como eixos a articulação da pesQuisa com a prática profissional( ${ }^{(9)}$.

O estudo foi realizado no HURNP, Que conta com 294 leitos, todos à disposição do Sistema Único de Saúde, situado no interior do Estado do Paraná.

Para a coleta de dados foram empregadas entrevistas semiestruturadas individuais e grupais gravadas, depoimentos escritos e documentos do núcleo, de 2003 a 2005. Das 76 enfermeiras Que freeüentaram as atividades, 36 participaram do estudo, sendo Que 12 participaram das entrevistas individuais e 30 das grupais; seis participaram das duas estratégias. A entrevista grupal foi realizada com cinco grupos de enfermeiros do serviço de enfermagem, constituídos por enfermeiras-assistenciais, por enfermeiras em cargo de chefia, outro com enfermeiras em assessorias e chefia do período noturno e um com enfermeiros Que haviam concluído ou estavam realizando cursos de pós-graduação stricto sensu. As entrevistas foram norteadas pela Questão: Qual a sua opinião sobre a prática de pesquisa por enfermeiros assistenciais após participar do NUPE ? O diário de campo foi utilizado para o registro de aspectos julgados interessantes pela primeira pesQuisadora ${ }^{(10)}$.

As participantes eram todas do sexo feminino, com idades variando de 28 a 53 anos, atuando na instituição de um a 26 anos, ocupando diferentes cargos na instituição.

Os princípios éticos foram seguidos: o estudo teve a aprovação do Comitê de Ética em Pesquisa da UEL, e todas as participantes concordaram em participar assinando o Termo de Consentimento Livre e Esclarecido.

A análise dos dados seguiu as seguintes etapas: 1) ordenação dos dados em textos e leitura repetida de todo o material obtido; 2) elaboração de categorias empíricas, ou seja, conceitos Que expressam a lógica interna do grupo (objeto) estudado; 3) elaboração de categorias analíticas, ou seja, os constructos teóricos 
do conhecimento do objeto e seus aspectos gerais, compreendidos e interpretados pelos pesquisadores, com as Quais construímos os sentidos $^{(10)}$.

\section{RESULTADOS E DISCUSSÃO}

Os sentidos manifestos por elas foram compreendidos a luz dos pressupostos Que mostram a pesquisa como processo de aprendizagem reconstrutivo ${ }^{(1)}$, além dos conceitos emitidos sobre a pesquisa como atitude e atividade investigativa inerente a uma boa performance profissional ${ }^{(12)}$.

Apresentamos a seguir a categoria Que aponta a importância da peseuisa na vida profissional.

\section{A valoração da atividade investigativa}

Os termos fundamental e importante foram freqüentemente usados nas entrevistas individuais e grupais, expressando a valoração da atividade investigativa para elas. Assim ouvimos:

Eu acho Que é fundamental pesquisar, prá gente não fazer mecanizado, pesquisar o dia a dia, ver o que está acontecendo na sua prática diária. Estudar, aprofundar. Fazer sabendo Quais as consequências. Como fazer melhor. (G6)

Acredito que a pesquisa é importante para todo enfermeiro assistencial. Ela possibilita o crescimento profissional. A Qualidade da assistência está diretamente relacionada à pesQuisa. (G4)

Para este grupo social, a pesquisa é tida como atividade importante, tanto pela expansão de conhecimento Que provoca, como pela incorporação de novas práticas Que possibilita.

Alguns estudos têm evidenciado, por parte das enfermeirasassistenciais, uma atitude positiva em relação à pesquisa, sem, contudo constituir-se aspecto determinante para a efetivação da atividade, devido a motivos de ordem estrutural e cultural nas organizações hospitalares ${ }^{(13)}$. Para as participantes do estudo, a pesQuisa possibilita a aQuisição, produção e aprofundamento de conhecimentos, a atualização e avaliação de suas práticas, o encaminhamento metodológico de soluções, o crescimento profissional pelo estímulo à reflexão sobre novas formas de conduzir seu trabalho e o despertar da paixão pelo conhecimento estruturado cientificamente $^{(5)}$.

O entendimento valorativo da atividade investigativa é um Quesito essencial para Que as enfermeiras-assistenciais sintam-se motivadas para a sua realização no cotidiano. Isto ocorre Quando elas percebem a importância dos resultados da sua pesquisa para a melhoria da assistência e o desenvolvimento profissional. No caso em estudo, podemos dizer Que esta atitude pró-ativa foi condição básica para Que houvesse ações e estratégias direcionadas a essa melhoria e Que reforçassem os movimentos de busca de reflexão do fazer profissional embasado em conhecimentos científicos. Com esse sentido, compreendemos uma retomada de valores culturais profissionais até então esQuecidos, devido à prática cotidiana do fazer sem reflexão.

\section{Pesquisar é Aprender}

Ao pesquisar, a enfermeira assistencial estuda, lê, busca, constrói conhecimento próprio e, assim, expande-se intelectualmente. $\mathrm{O}$ processo intrínseco ao desenvolvimento do raciocínio investigativo associado à experiência de consumir e produzir conhecimento de forma sistematizada propicia ao enfermeiro a atitude de estar de olhos abertos para a realidade Que, no exercício de problematizar, interpretar e dialogar, aprende em sentido criativo ${ }^{(1)}$. Esse é um processo de aprendizado contínuo que se expande para além do conhecimento do tema em si, provocando novas concepções, atitudes e possibilidades na recriação da própria maneira de ser e cuidar/assistir. Ressaltando o momento de aprendizado possibilitado pela pesquisa, ouvimos:

A gente começa a estudar um assunto pra entender melhor sobre este assunto, então a pesQuisa, acima de tudo, ela é aprendizado. (E2)

A pesquisa 'abre' a cabeça dos enfermeiros assistenciais e possibilita uma visão global.

(G2)

O aprendizado por meio da pesquisa favorece o desenvolvimento do hábito de leitura e da redação científica, capaz de levar a descoberta e a resolução de problemas, foi assim ressaltado:

[...] a gente vai aprendendo a escrever, aprendendo a ler. Então, isso enriquece muito o nosso dia a dia em termos de produção de trabalho científico. (E9)

[...] de você ter a satisfação de ir lá, de ler, de refletir, de pensar. É muito bom esse momento da descoberta. Quando você faz as ligações. Você junta um pedacinho daQui, um pedacinho dali, Que você leu e daí você constrói uma idéia, uma possibilidade e resolução dos problemas. (E7)

$\mathrm{O}$ ato de pesquisar também é visto como uma atividade Que predispõe a enfermeira ao estudo e, conseQüentemente, a uma aprendizagem mais efetiva e significativa, à consciência de precisar se aperfeiçoar. Assim ouvimos:

Eu acho Que a pesquisa me fez crescer. Eu só aprendi sobre um assunto porQue eu comecei a estudar, porQue Queria escrever artigos. Então conforme a gente pesQuisava um tema, eu me sentia mais segura de debater com algum médico, de orientar o funcionário. Estudando para escrever o artigo, eu estava aprendendo. (E I)

Eu aprendi bastante a escrever, isso é importante, apesar de Que eu ainda tenho um pouQuinho de dificuldade para colocar as palavras em ordem. (E9)

A importância de se compreender a aprendizagem como fenômeno reconstrutivo, em Que a pesquisa é ressaltada como processo de aprendizagem, é defendida pela noção de Que a atividade investigativa precisa fazer parte de todo processo educativo, em Qualquer nível e em Qualquer fase ${ }^{(1)}$.

Nesse sentido é necessário distinguir o pesquisador profissional, sujeito Que vive de produzir conhecimento, do profissional pesquisador, aquele Que usa a pesQuisa como propedêutica de seu 
saber. Nesta segunda classificação encontra-se a enfermeira assistencial Que, pela pesquisa, é motivada a construir seu caminho, passando por etapas sucessivas, pelas Quais ela se eleva a patamares mais avançados e complexos. É um caminho de emancipação, pois ao colocar o cérebro para funcionar, ou seja, pesquisando com sistematicidade ou sabendo pensar, gera modos alternativos de intervenção na realidade ${ }^{(I)}$.

É importante considerar Que de fato, nem todo enfermeiro será pesquisador, no sentido stricto; porém, para Que ele possa ter segurança sobre a eficácia do cuidado de enfermagem oferecido, ele depende de uma base científica sólida e, para tanto, todo enfermeiro deve sim, estar engajado em atividades de pesquisa.

O sentido de pesquisar, como um movimento intenso do pensamento associado à consciência crítica e criativa, de Quem sabe pouco, e Que o conhecimento aprofundado reflete na prática assistencial, foi assim manifestado pela enfermeira:

[...] enquanto eu pesquiso, eu estudo. Quanto mais eu estudo, menos eu sei. Quanto menos eu sei, mais eu vou estudar. Quanto mais eu estudar, melhor. $O$ estudo reflete na minha prática do dia a dia. (E3)

Demo $^{(11)}$ esclarece estes sentidos, colocando dois cenários. Primeiro, é importante ler a realidade com olhos abertos, sendo um dos pontos centrais da aprendizagem reconstrutiva a idéia, pois "não se pode Questionar sem ser Questionado, não se pode arrumar consciência crítica sem tê-la, não se pode avaliar sem ser avaliado".

O autor expõe como segundo ponto que "o saber pensar não é apenas pensar, mas a base teórica para poder intervir melhor". O pensar é então, uma habilidade Que reforça o entendimento de Que a essência do conhecimento é ser a intervenção mais prática dos tempos. E conclui citando: "Um projeto de intervenção só tem a ganhar força se for orientado devidamente pela teoria, bem como a teoria, para ser deste mundo, precisa confrontar-se com a prática"(11).

O conceito da cultura nos ajuda a fazer uma leitura apropriada do processo de aprendizagem. A aprendizagem propiciada pela atividade investigativa é decorrente de um processo social, entre pessoas e o meio Que as cerca. Sendo assim, podemos imaginar Que existe o antes e o depois no processo de aprendizagem. A enfermeira, antes do início da atividade investigativa, em muitas situações, é alguém Que age por rotina, empiricamente e, após a aprendizagem, ao buscar e aplicar a evidência científica no contexto profissional, ela assume a postura de um novo ser, transformado e transformador das práticas no processo de cuidar.

O movimento empreendido na elaboração de uma pesquisa possibilita também o crescimento e o aprendizado de todos os membros da equipe de enfermagem. Trazemos este exemplo:

EnQuanto profissional você cresce muito, então você acaba crescendo junto com todo mundo Que trabalha com você. [...] (E8)

Percebemos Que a pesquisa tem implicações em múltiplas direções, isto é, possibilita a aprendizagem pessoal, pela expansão da visão do mundo social e profissional, mobiliza o hábito da leitura e escrita, a reflexão, a argumentação, a síntese e, por conseguinte, possibilita uma nova maneira de pensar e agir. Todo esse movimento, Quando socializado com os pares, pode levar ao crescimento de todos e, consequentemente, a uma melhor maneira de cuidar.

Contudo, apreendemos que a enfermeira traz seus saberes teórico-práticos anteriores para esse processo de pesquisar e Que estes são valorizados e incorporados na construção do novo saber. Isto implica uma transformação profissional na sua ação de cuidar em saúde, tornando-se mais competente e compromissada com o exercício da profissão.

\section{Movimentos da Atividade Investigativa}

Entre os aspectos intrínsecos da prática investigativa, as enfermeiras apontaram vários movimentos Que são desenvolvidos, desde a sua atitude diante do problema, a sua reação e transformação na busca das respostas e, ainda, o estado de permanente aprendizagem no mundo profissional.

O sentir-se movida por um Questionamento, por um problema é a condição básica Que desperta na enfermeira uma atitude investigativa. Caracterizamos assim este entendimento:

A pesquisa é você ir buscar alguma coisa Que satisfaça uma indagação, um Questionamento: - Será Que isso é isso mesmo?(E7)

O cotidiano do cuidado é rico em situações e atribulações Que podem, muitas vezes, transformarem-se em indagações, inquietações e objeto de pesquisa. Partindo do pensamento de Que pesquisa é "uma atividade intelectual e um labor que resulta da relação do homem com o mundo, como um observador, indagador e interventor", podemos explorar o sentido manifesto da pesQuisa como ineuietação da enfermeira, a Qual, ao observar a realidade Que a cerca, consegue identificar situações Que fogem do esperado. Nesta situação ela indaga por Que tal fenômeno está acontecendo e pode chegar a intervir, dando respostas as ineuietações ${ }^{(14)}$.

A rigor, a atitude e a atividade científica são coisas diferentes. A atitude científica é uma dimensão pessoal, uma característica nãoexclusiva dos cientistas profissionais, mas que se encontra difusa nas pessoas da sociedade em geral. Por outro lado, a atividade científica é uma atividade desenvolvida por indivíduos de uma parcela da comunidade, e está relacionada a uma ocupação de natureza profissional, sendo decorrente de um aprendizado obtido de forma praticamente exclusiva na convivência institucional, de acordo com paradigmas normativos ${ }^{(12)}$.

Interessa-nos aprofundar a compreensão sobre a atitude investigativa Que é filha do bom senso, do espírito crítico que uma pessoa desenvolve desde os primeiros anos de atividade intelectual, bem como uma relação sadia Que a pessoa estabelece com os outros e com o mundo, ou seja, a atitude investigativa existe num estado de espírito Que compreende uma disposição emocional e uma organização intelectual Que permite às pessoas poder duvidar das idéias Que lhes relatam, para Que possam vir a aceitá-las como verdadeiras e valorizá-las ou recusá-las por compreenderem-nas falsas e combatê-las ${ }^{(12)}$.

Com esse sentido, ouvimos o seguinte relato de uma enfermeira:

A pesquisa é aquela perguntinha que está sempre no sue cérebro e você não acha resposta. Então você, baseada na necessidade da resposta, vai atrás. (E3) 
Tal discurso expressa a atitude investigativa da enfermeira assistencial pelas situações do cotidiano profissional e Que ela, pela indagação, se sente inQuietada e mobilizada à busca de respostas. É o movimento de reflexão-ação movido pelas circunstâncias, ações, pessoas Que fazem parte do contexto pessoal, profissional e organizacional.

Entretanto, o importante é atingir, pela atitude investigativa, o Questionamento reconstrutivo, Que se apresenta duplamente provocativo,

Há Que parecer o desafio do Questionamento: um sujeito capaz de perguntar, ineuirir, duvidar, contrapor-se, confrontar-se, significando sobretudo capacidade de autonomia e a habilidade de saber pensar; há Que parecer o compromisso da reconstrução: à crítica deve seguir a contraproposta, devidamente reconstruída, na Qual comparece a competência humana pertinente e capaz de intervir na prática ${ }^{(11)}$.

Ainda sobre a discussão da pes@uisa como uma ineuietação do profissional, acrescentamos a reflexão sobre o pesQuisar e ensinar a pesquisar na enfermagem, Que é descrita como uma atitude primordial, pois os problemas sempre são emergentes da prática de cuidar e de ensinar a cuidar, ou se referem à totalidade da prática da enfermagem. Portanto, nem os conceitos e definições são intocáveis. Tudo merece Questionamento, discussão e análise, bem como submissão às regras da demonstração e das provas"(15).

A inquietação é um primeiro movimento Que, se é estimulante para a enfermeira, provoca a busca da comprovação da evidência científica para um fazer com conhecimento cientificamente comprovado. Este sentido é, no pensar das enfermeiras, aspecto marcante da atividade investigativa, reiterado nos depoimentos $\mathrm{e}$ exemplificado abaixo:

Eu acho que a pesquisa, hoje ela tem que ser muito em cima da prática. Hoje se fala muito em prática baseada em evidência. Você vai buscar elementos Que subsidiam a tua prática. (E3)

A palavra evidência ressalta o Quanto este conceito é importante na cultura do conhecimento científico de uma profissão dominada por rotinas e rituais, como a enfermagem.

A evidência científica rompe com o velho paradigma do fazer respaldado na norma, rotina, no continuísmo empírico. Este linguajar tem sido empregado mais recentemente no campo da saúde, a partir da abordagem Que incorpora as evidências oriundas de pesquisas, a competência clínica e as preferências do cliente para a tomada de decisão sobre a assistência à saúde, denominada de prática baseada em evidências ${ }^{(5)}$.

A importância da evidência científica para a profissão decorre da possibilidade de instaurar a relação do raciocínio científico com a prática de peşuisa, situação essencial para a aproximação de uma enfermagem baseada em evidências, como se observa no panorama mundial ${ }^{(5)}$.

Para tanto, é mister provocar um movimento Que estimule os profissionais a procurar a repensar e refazer a prática Que muitas vezes é inconsistente, fragmentada e pautada na autoridade e em observações não-sistematizadas e não-científicas. A busca da evidência científica é um paradigma assistencial e pedagógico, e como uma ferramenta Que se bem usada pode modificar os resultados, refletindo uma assistência de Qualidade e na redução dos custos dos serviços de saúde ${ }^{(5)}$.

No caso em estudo, existe um movimento ativo das enfermeiras voltado para a aplicação de evidências Que leva, num primeiro momento, a buscar por informações, decidindo-se pela atividade investigativa como caminho para a resolução das dificuldades da prática.

O movimento intrínseco à atividade investigativa, gerado pela inQuietação e a busca da evidência científica, possibilita a valorização da atividade assistencial. Este sentido surgiu nos depoimentos percebidos como fator de estímulo à enfermeira que pesquisa e é, por isso, exposta à influência de novos valores (evidências) relacionados aos procedimentos de enfermagem, uma poderosa arma contra os rituais desta prática. Neste sentido ouvimos:

Uma profissão é valorizada, Quando você faz um trabalho científico, Quando você demonstra Que aQuilo que você se propôs a fazer, de certa forma deu resultado. (E8)

É através da pesquisa que você dá um pulo muito maior e você consegue fazer esse cuidar, que seria meio intuitivo até, de uma forma muito mais racional, muito mais científica. (G I4)

O valor da pesQuisa para o fortalecimento da profissão foi apresentado no depoimento:

$O$ enfermeiro assistencial vive a prática no dia-a-dia e suas pesquisas valerão para o crescimento da enfermagem como profissão. (G3)

É interessante apreender nos depoimentos, a valorização da atividade investigativa no contexto profissional da enfermeira, como fator propulsor de mudanças no cotidiano do cuidar, integrando as evidências do conhecimento científico ao cuidado humano oferecido pela enfermagem.

\section{Atividade Investigativa é trabalho árduo Que demanda esforço pessoal}

Ao mesmo tempo em Que as enfermeiras expressaram a importância da pesQuisa para a prática profissional, elas também manifestaram claramente Que se trata de uma atividade Que só ocorre com empenho pessoal. Assim, observamos o sentido de Que fazer pesquisa é tarefa árdua:

[...] levantar problema não é fácil, fazer levantamento de dados não é fácil, você compilar dados não é fácil, você ir atrás de referência bibliográfica não é fácil e não é barato, porQue você tem que buscar fora. (E3)

É difícil ainda, eu insisto em dizer, pelas poucas oportunidades Que a gente tem de tempo, envolvimento com o trabalho. (EI2)

Acho que por isso, para você escolher uma pesQuisa, primeira coisa você tem que falar 'gosto disso' (... É É isso Que ajuda pra você passar, se não você não agüenta, por Que é sofrido. (El)

Autores concordam sobre o empenho necessário a ser dado à produção de pesQuisa, porQue esta demanda esforço pessoal na 
busca de informações sobre o fenômeno em estudo, toma tempo e muitas vezes esgotam, podendo culminar em obras de arte como resultado de exaustivo labor técnico e científico ${ }^{(5,14)}$.

Contudo, é possível tomar gosto pelo saber pensar, por meio da pesquisa, desde Que esta ação não seja concebida a maneira de Quem não sabe pensar, ou de Quem apenas reproduz ou ainda de Quem encara a pesquisa como tarefa penosa. Quando o indivíduo percebe que o conhecimento crítico é a bagagem mais decisiva para enfrentar as Questões da vida e do mercado de trabalho, mais facilmente adere ao processo sistemático de conhecer, reconstruir, crescendo com ele ${ }^{(1)}$.

A superação do sentimento de trabalho exaustivo pode ainda ter o entendimento de Que estudar dá trabalho e pode cansar. Porém, se pode extrair a satisfação desta situação Que "não é a alegria da superficialidade, banalização, encurtamento, macetes, mas aquela Que enche a alma"(II).

Complementando a citação anterior, o trabalho árduo numa atividade investigativa, pode ser suavizado Quando a estrutura formativa e assistencial incorpora diferentes estratégias Que visam dar sustentação à enfermeira-pesquisadora, como o desenvolvimento de habilidades de estudo, de leitura e redação de textos científicos, participação em cursos de metodologia científica, orientação de trabalhos científicos, etc.

Até este ponto, podemos sintetizar Que, para as enfermeiras informantes do estudo, a pesQuisa é um elemento-chave no processo de cuidar, no crescimento e aprendizado pessoal e da equipe. A atividade investigativa acontece mediante alguns movimentos Que se entrelaçam $3 / 4$ da inquietação à busca de melhores respostas para uma ação profissional mais adequada e profícua, Que pode Qualificar cientificamente a atividade assistencial. Contudo, fazer pesquisa é trabalho árduo, Que demanda esforço pessoal, pressupõe perseverança da enfermeira-pesQuisadora Que, ao se lançar nessa tarefa, prova o sabor agridoce da atividade investigativa, experimentando a dualidade entre o ato trabalhoso e o prazeroso, entre a inQuietação e a descoberta.

Estes sentidos são específicos para o grupo envolvido no estudo, frente às suas características pessoais, profissionais e o contexto da cultura organizacional Que o circunda.

\section{CONSIDERAÇÕES FINAIS}

Os sentidos da atividade investigativa na prática profissional de enfermeiras assistenciais, apoiadas por um serviço de assessoria em pesQuisa, trouxeram a manifestação da valoração da atividade como condição primordial de motivação para Que as enfermeirasassistenciais realizem tal prática no seu cotidiano.

As enfermeiras também sinalizaram sobre os movimentos e finalidades inerentes a atividade investigativa, Que parte da inquietação, mobiliza a busca da evidência científica e possibilita a sustentação e valorização da atividade assistencial. São sentidos Que fortalecem o entendimento da atividade como estratégia de renovação de conhecimentos, atitudes e comportamentos para um cuidar Qualificado cientificamente.

Apontaram que o desenvolvimento de pesquisa é uma tarefa árdua e Que demanda esforço pessoal. De todo modo, as próprias enfermeiras expressam Que a superação deste fator está na consciência da necessidade e do prazer decorrente do ato de pesquisar, Quando concebido como desafio e caminho para a elaboração criativa de soluções transformadoras.

A pesquisa, como atividade acessível e factível a enfermeira assistencial, possibilita-lhe resgatar a auto-estima profissional, o desenvolvimento técnico-científico, a produção de saberes e transformações na prática, enfim, construir novas idéias e práticas, transformando sua cultura profissional.

Frente aos resultados do estudo consideramos que o setor responsável pela educação permanente dos profissionais, das organizações hospitalares, deve empenhar-se na missão de capacitálos e de promovê-los, assumindo a responsabilidade de instrumentalizá-los e apoiá-los no trabalho de pesquisa. Assim, a pesquisa, como ferramenta de trabalho, poderá impulsionar os profissionais a produzirem conhecimentos Que auxiliem na compreensão daQuilo Que se lhes propõe para um fazer aberto às indagações e reconstruções.

Finalizando, a formação do NUPE foi considerada uma proposta ousada e com bons resultados, mostrando Que a união de gestores, educadores e profissionais possibilita a criação de uma cultura de peseuisa no contexto da enfermagem assistencial.

\section{REFERÊNCIAS}

I. Trentini M, Paim ML. Pesquisa convergente-assistencial: um desenho Que une o fazer e o pensar na prática assistencial em saúde-enfermagem. Florianópolis: Insular; 2004.

2. Santos TCF, Gomes MLB. Nexos entre pós-graduação e pesquisa em Enfermagem no Brasil. Rev Bras Enferm 2007; 60(1): $91-5$.

3. Cassiani SHB, Passarelli LR. Pesquisa em enfermagem: um processo de ação do enfermeiro. Rev Gaúcha Enferm 1999 20(1): $91-110$.

4. Castilho V, Kurcgant P. O vivencial de enfermeiros: assistenciais no desenvolvimento de pesquisa nas organizações hospitalares. Mundo da Saúde 1999; 23(3): 159-66.

5. Guariente MHDM. Articulação da atividade investigativa com a prática Professional - processo e produto de enfermeiras apoiadas por um núcleo de pesquisa [tese]. Ribeirão Preto: Escola de Enfermagem de Ribeirão Preto, Universidade de São Paulo; 2006.

6. Dyniewicz AM, Gutiérez MGR. Metodologia da pesquisa para enfermeiras de um hospital universitário. Rev Latino-am. Enfermagem 2005; I3(3): 354-63.

7. Guariente MHDM, Zago MMF. Scientific production of nurse clinicians mediated by research advisory group. Rev Latinoam Enfermagem 2006; 14(3): 330-5.

8. Geertz C. O saber local - novos ensaios em antropologia interpretativa. Petrópolis: Vozes; 1997.

9. Rosenberg IP, Yares PM. Schematic representation of case study research designs. I Adv Nurs 2007; 60(4):447-52.

10. Minayo MCS. O desafio do conhecimento: pesquisa Qualitativa em saúde. 10ª ed. São Paulo: Hucitec, 2007.

11. Demo P. Pesquisa: princípio científico e educativo. $8^{\mathrm{a}}$ ed. São Paulo: Cortez; 2001.

12. Turato ER. Tratado da metodologia da pesquisa clínicoQualitativa: construção teórico-epistemológica, discussão 
Sentidos da pesquisa na prática profissional de enfermeiras assistenciais

comparada e aplicação nas áreas da saúde e humanas. Petrópolis: Vozes; 2003.

13. Castilho V. Educação continuada em enfermagem: a pesquisa como possibilidade de desenvolvimento de pessoal. Mundo da Saúde 2000; 24(5): 357-60.
14. Soubhia Z, Garanhani ML, Dessunti EM. O significado de aprender a pesQuisar durante a graduação. Rev Bras Enferm 2007; 60(2): 178-83.

15. Carvalho V. Cuidando, pesquisando e ensinando: acerca de significados e implicações da prática de enfermagem. Rev Latino-am Enfermagem 2004; 12(7): 806-15. 